\title{
Illiquidity and the Risk of Stock Market Crash
}

\author{
Yaping Wang1, Zhaohui Wang2*, Yi Dang2 \\ ${ }^{1}$ School of Economics, Jinan University, Guangzhou, China \\ ${ }^{2}$ College of Commerce, Ningbo University, Ningbo, China \\ Email: ${ }^{*}$ wangzhaohui@nbu.edu.com
}

How to cite this paper: Wang, Y. P., Wang, Z. H., \& Dang, Y. (2020). Illiquidity and the Risk of Stock Market Crash. American Journal of Industrial and Business Management, 10, 421-431.

https://doi.org/10.4236/ajibm.2020.102028

Received: January 14, 2020

Accepted: February 22, 2020

Published: February 25, 2020

Copyright $\odot 2020$ by author(s) and Scientific Research Publishing Inc. This work is licensed under the Creative Commons Attribution International License (CC BY 4.0).

http://creativecommons.org/licenses/by/4.0/

\begin{abstract}
This paper aims to study the impact of illiquidity on the risk of stock market crashes. Through empirical research on daily and weekly data of the Shanghai Composite Index, it is found that high liquidity can relieve the risk of stock market crash. For this reason, this article proposes to establish a stock market liquidity monitoring and early warning mechanisms, rationally control market leverage, and strengthen supervision of hot money.
\end{abstract}

\section{Keywords}

Stock Market Crash, Illiquidity, Market Risk

\section{Introduction}

The Great Collapse of the United States in 1929 and Black Monday in 1987 brought a strong impact to the market, accompanied by the depletion of liquidity Simultaneous. The stock market crash has been accompanied by a depletion of liquidity. Studying the influence of liquidity on the risk of stock market crash is of great significance to the stable operation and healthy development of national financial market.

After reviewing existing literatures, it is found that the current research on the impact of liquidity on the risk of stock market crashes is divergent both at the market level and at the company level. In addition, in terms of quantity, more research focuses on the company level, the research object is individual stocks, the market as a whole, and relatively few studies are carried out from the perspective of systemic risk in the broader market. The overall collapse risk of the stock market is related to the stable operation and healthy development of a country's financial market, and its importance is self-evident. Moreover, in the existing studies, the time of the data used is mostly annual, and the annual calculation of the risk of collapse is calculated and studied. This article believes that, 
from the perspective of the actual needs of the secondary market, the annual crash risk indicators, for both regulators and investors, lack early warning significance. For this reason, this article takes the broad market index as the research object, and uses daily and weekly data to measure the crash risk indicator. From the perspective of systemic risk, it explores the impact of liquidity on the overall crash risk of the stock market, with a view to the research results being able to market management. It has practical reference significance.

The following chapters of this paper were organized as below. In Chapter 2, this paper did a literature review and summarized other researchers' work on the market liquidity and the impact of liquidity on the risk of stock crash from the corporate level. In Chapter 3, this paper explained the theoretical basis of measurement of stock market crash risk, liquidity and control variables, and set up models which will be used to analyze the impact of illiquidity on the stock market crash. In Chapter 4, the paper explained the collecting process of data, presented the descriptive statistics of all the variable and showed empirical results. In Chapter 5, this paper gave research conclusions and policy recommendations.

\section{Literature Review}

The black hole of liquidity (Persaud, 2007) believes that liquidity in the market suddenly disappeared for some reason, and the number of sellers is much larger than that of buyers. In order to close transactions quickly, asset prices are continuously reduced, but selling orders continue to increase, and liquidity continues to deteriorate. The liquidity of the entire market seems to be swallowed up instantly. The root cause of this extreme phenomenon of liquidity black holes is that in a very short period, the behavior of investor groups is highly consistent, extreme homogeneity has occurred, and investors in the market have all become sellers. The liquidity spiral theory (Brunnermeier \& Pedersen, 2008) believes that liquidity can be divided into market liquidity and financing liquidity. Market liquidity measures the difficulty of market transactions, and financing liquidity measures the difficulty of investors' financing. Investors' ability to provide market liquidity depends on their financing capabilities. Conversely, investors' ability to load financing and margin also depends on market liquidity. Under certain conditions, the mechanism of mutual strengthening of market liquidity and financing liquidity has led to a liquidity spiral. When the stock asset price drops sharply, investors need additional margin due to the existence of leverage. At the same time, financing liquidity also begins to decline. Investors have to sell stocks eagerly, and market liquidity deteriorates. The stock price is getting lower and lower, the margin gap is getting bigger and bigger, and the liquidity of financing cannot be satisfied. Investors can only sell their assets, and the market liquidity deteriorates further. In this cycle, a liquidity spiral is formed.

In addition to the market level, more scholars have studied the impact of liquidity on the risk of stock crash from the corporate level. From the perspective of information production efficiency, Holmstrom \& Tirole (1993) and Holden et 
al. (2014) believe that higher stock liquidity improves informed trading, and its stock price can more fully and fully reflect the information of this company. Admati and Pfleiderer (2009) from the perspective of managerial compensation, Maug (1998) from the perspective of corporate governance, which higher stock liquidity is helpful to external supervision of company managers and reduces managers' inefficient investment decisions probability to avoid the occurrence of bearish events from the source, thereby reducing the risk of a stock market crash. However, based on short-term behavior theory, Porter (1991) and Fang et al. (2014) believe that high liquidity will attract more institutional investors who are too concerned about the company's short-term performance, forcing company managers to choose to use hidden news to exaggerate short-term performance. And take measures to alleviate downward pressure on stock prices, thus accumulating risks. Bhide (1993) and Edmans (2009) proceeded from the threat of the exit mechanism of large shareholders, and believed that the higher the liquidity, the more beneficial it is for large shareholders to withdraw. When bad news is announced, strong selling pressure from large shareholders will amplify the negative market news to the company response, thereby increasing the risk of a company's stock price crashing.

\section{Models and Variables}

\subsection{Measurement of Stock Market Crash Risk}

With reference to the research of Chen et al. (2001), this paper uses the negative skewness coefficient to measure the risk of stock market crash. The daily (weekly) rate of return of the Shanghai Composite Index uses the logarithmic rate of return:

$$
R_{t}=\ln P_{t}-\ln P_{t-1}
$$

$P_{t}$ is the closing price on the $t$ day (week) of the market, and $R_{t}$ is the corresponding logarithmic rate of return.

$$
N C S K E W_{t}=-n\left[(n-1)^{3 / 2} \sum R_{t}^{3}\right] /(n-1)(n-2)\left(\sum R_{t}^{2}\right)^{3 / 2}
$$

$n$ is a rolling parameter, which represents the logarithmic yield data of the previous $n$ trading days (weeks) to be used in calculating the market's t-day (week) crash risk. NCSKEW $W_{t}$ indicates the negative skewness coefficient of the market on the $t$ day (week). A larger value means a higher risk of a market crash.

The design idea of this indicator is the skewness coefficient. The reason why this indicator is selected in this paper is based on the following two considerations:

First, skewness is a statistic that describes the symmetry of the distribution of variable values. For a normal distribution, if it is a standard distribution, the skewness coefficient is 0 ; if it is a non-standard distribution, a positive value indicates that the distribution is right-skewed; a negative value indicates that the distribution is left-skewed. Behavioral finance believes that at different stages, people's reactions to positive and negative news are not the same, so the proba- 
bility that $R_{t}$ is in the rising and falling stages is not the same, and its distribution is naturally not unskewnessed. In the rising phase, people are gradually entering a state of enthusiasm, which are sensitive to positives and tend to ignore negatives. When the downturn occurs, people will seriously consider the negative news, be sensitive to bearishness, and tend to ignore the goodwill. In an atmosphere of panic, it is easy to amplify the reaction to negative news, and $R_{t}$ will drop significantly. As shown in the distribution chart, $R_{t}$ will show a left-skewnessed state. The more the tail is to the left, the greater the market decline and the greater the absolute value of the skewness coefficient, which also means the higher the risk of crash. The value of the skewness coefficient can be positive or negative. The negative value of greater absolute value means the higher the risk of a crash. For the convenience of research, it is negative, so it is called negative skewness coefficient (Chen et al., 2001).

Second, data frequency is different. Compared with the existing research, the main feature of this article is that it takes the overall market and the broad market index as research objects, and measures the market's daily and weekly crash risk. Traditional research uses company-annual data, which means, using annual as the unit, using a company's daily (weekly) rate of return data for a year to calculate the company's collapse risk this year. This paper believes that using the annual stock market crash risk indicator as unit is lacking in early warning significance for the regulators and investors and is out of touch with the market from the perspective of the practical application of the secondary market. For this reason, this article attempts to measure the daily and weekly market crash risk by using the rolling parameter $n$, which is the current day (week) crash risk index, and using the previous day (week) return data to calculate.

\subsection{Measure of Liquidity}

This article uses Amihud's (2002) liquidity ratio (Amihud illiquidity) as a measure of liquidity:

$$
\operatorname{Liq}_{t}=-\left|R_{t}\right| / \mathrm{Vol}_{t}
$$

$\left|R_{t}\right|$ is the absolute value of the market index's return on the $t$ trading day (week), and $\mathrm{Vol}_{t}$ is the transaction amount of the entire market on the $t$ trading day (week). The price change caused by unit turnover. The higher the ratio, the greater the impact of the unit transaction amount on the price, and the lower the stock's liquidity. In order to facilitate the logical understanding, the negative value is taken to make the meaning of the formula become: The higher $L_{i q}$ means the higher the stock's liquidity.

\subsection{Control Variable}

In the current research on stock liquidity and the risk of stock market crashes, the selected control variable is mostly the company-annual indicator. The focus of this study is the systemic risk of the broader market, and the time frequency of the data used is weekly, so these company-annual indicators used in previous 
studies cannot be used. After referring to the research by Chang et al. (2016), Christoffersen et al. (2016) and others, it was decided to use the market rate of return Ret $_{t}$ and the rate of return volatility Sigma ${ }_{t}$ as the control variables.

\subsection{Model Settings}

In order to verify the impact of the hypothetical $\mathrm{H}$-share liquidity on the stock market crash risk, this paper constructs the following model:

$$
\text { Crash Risk }{ }_{t}=\beta_{0}+\beta_{1} \text { Liq }_{t}+\beta_{2} \text { Ret }_{t}+\beta_{3} \text { Sigma }_{t}+\varepsilon_{t}
$$

The dependent variable Crash Risk ${ }_{t}$ represents the crash risk of the broad market index on the $t$ trading day (week), which is measured by $N C S K E W_{t}$; the independent variable $\mathrm{Liq}_{t}$ represents the broad market index on the $t$ trading day (week). The control variables Ret $_{t}$ and $S_{\text {igma }}$, represent the returns and volatility of the broad market index on the $t$ trading day (week), respectively.

\section{Empirical Results and Analysis}

\subsection{Sample Selection}

This article selects the Shanghai Composite Index as a sample from the ten years from 2009.1.1 to 2018.12.31. This period covers different market cycles and ensures the comprehensiveness of the sample. In addition, since the result calculated by the independent variable $\mathrm{Liq}_{t}$ is very small, for the convenience of research, it is enlarged 1012 times here. The data comes from the Wind database, and the frequency of the data used is divided into daily and weekly.

Regarding the rolling parameter $n$, Chen et al. (2001) did not give a value criterion when constructing the indicator. Therefore, in addition to considering the minimum effective number of samples, this paper also refers to the moving average indicator system in stock trading, and assigns a series of different values to the rolling parameter $n$, which is $20,40,60,80,100$ in turn, for calculating a series of crash risk indicators with different parameter values.

\subsection{Stationary Test}

Showing in Table 1 and Table 2. It can be seen that the $t$ statistic of each index is less than the critical value of the significance level of $1 \%$ or $5 \%$. It can reject the null hypothesis and judge the sequence without unit roots with $99 \%$ or $95 \%$ certainty. So it's stationary sequence.

Table 1. Stationary test of daily sample data.

\begin{tabular}{ccccccc}
\hline variable & Obs. & t-Static & Prob. & $1 \%$ level & $5 \%$ level & $10 \%$ level \\
\hline Ncskew & 2410 & -8.0690 & 0.0000 & -3.4329 & -2.8625 & -2.5673 \\
Liq & 2410 & -6.8245 & 0.0000 & -3.4329 & -2.8625 & -2.5673 \\
Ret & 2410 & -47.4229 & 0.0001 & -3.4329 & -2.8625 & -2.5673 \\
Sigma & 2410 & -3.5129 & 0.0078 & -3.4329 & -2.8625 & -2.5673 \\
\hline
\end{tabular}


Table 2. Stationary test of weekly sample data.

\begin{tabular}{ccccccc}
\hline variable & Obs. & t-Static & Prob. & $1 \%$ level & $5 \%$ level & $10 \%$ level \\
\hline Ncskew & 490 & -3.3260 & 0.0143 & -3.4436 & -2.8673 & -2.5699 \\
Liq & 490 & -6.9522 & 0.0000 & -3.4436 & -2.8673 & -2.5699 \\
Ret & 490 & -20.6338 & 0.0000 & -3.4436 & -2.8673 & -2.5699 \\
Sigma & 490 & -2.5300 & 0.1089 & -3.4436 & -2.8673 & -2.5699 \\
\hline
\end{tabular}

\subsection{Regression Analysis of Daily Sample Model}

According to Equation (2), regression analysis of the daily collapse risk indicator $N C S K E W_{t}$ with different rolling parameter values is performed, and the results are as in Table 3.

Analyze Table 3. Except for the model represented by $n=100$, the t-tests for the independent variables $\operatorname{Liq}_{t}$ of the other models all passed significantly. This article argues that the risk of a crash is most relevant to recent information. When the value of the rolling parameter $n$ is small, the crash risk indicator will be more sensitive and can reflect the crash situation of the stock market more quickly; otherwise, the response of the crash risk indicator will change because it covers more information before the market fluctuations are flat. Because the stock market crash is characterized by its rapid and powerful characteristics, it is relatively rare to experience continuous sharp declines. If you consider too much information when the stock market is stable, the impact of the crash will be weakened. Moreover, the regression coefficient of the independent variable $\mathrm{Liq}_{t}$ ranges from -1.5248 to -0.2544 , and its absolute value decreases monotonically. Firstly, it means that liquidity can reduce the risk of a stock market crash. Secondly, it means that as the rolling parameter $n$ gradually increasing, the ability of liquidity to explain the risk of a crash gradually becomes weaker. Therefore, this article first discards the models that fail the t-test with $n=100$, and also discards the two models with weak interpretation ability, $n=60$ and $n=80$, and finally retains strong interpretive model, $n=20$ and $n=40$. Even if both are retained, it must be understood that $n=20$ still performs better than the model represented by $n=40$ and has a stronger interpretation ability. In order to verify this assertion, this paper conducts Granger causality tests on the risk indicators of the two models, and the results are as in Table 4.

It can be seen from Table 4 that the crash risk indicator NCSKEW_20 at $n=$ 20 is not the Granger cause of the crash risk indicator NCSKEW_40 at $n=40$. The associated probability is 0.0073 , which can reject the null hypothesis at a significance level of 1\%. It means NCSKEW_20 is the Granger reason for NCSKEW_40. In contrast, NCSKEW_40 is not the Granger cause of NCSKEW_20. This means that statistically, it can be considered that $n=20$ was already given before the crash risk indicator with $n=40$ was given a signal. In other words, when calculating the risk of a crash, a crash risk indicator with $n=20$ will be more sensitive and can more quickly reflect the crash of the stock market. 
Table 3. NCSKEW regression results of daily sample data.

\begin{tabular}{cccccc}
\hline \multirow{2}{*}{ variable } & NCSKEW $_{t}$ & NCSKEW $_{t}$ & NCSKEW $_{t}$ & NCSKEW $_{t}$ & NCSKEW $_{t}$ \\
\cline { 2 - 6 } & $(n=20)$ & $(n=40)$ & $(n=60)$ & $(n=80)$ & $(n=100)$ \\
\hline \multirow{2}{*}{ Liq $_{t}$} & $-1.5248^{* * *}$ & $-1.2284^{* * *}$ & $-0.5743^{* * *}$ & $-0.3741^{* *}$ & -0.2455 \\
& $(-5.7923)$ & $(-5.7771)$ & $(-3.0764)$ & $(-2.2477)$ & $(-1.5772)$ \\
\hline \multirow{2}{*}{ Ret $_{t}$} & $-2.4513^{*}$ & -1.3332 & -0.8555 & -0.9539 & -1.1875 \\
& $(-1.6391)$ & $(-1.1004)$ & $(-0.8033)$ & $(-1.0014)$ & $(-1.3300)$ \\
\hline \multirow{2}{*}{ Sigma $_{t}$} & $41.0144^{* * *}$ & $40.2971^{* * *}$ & $41.0422^{* * *}$ & $43.1319^{* * *}$ & $45.2505^{* * *}$ \\
& $(12.5901)$ & $(14.6555)$ & $(16.3494)$ & $(18.7629)$ & $(20.5685)$ \\
\hline
\end{tabular}

Note: ${ }^{*}, *$, and ${ }^{* * *}$ represent the significance levels of $10 \%, 5 \%$, and $1 \%$, respectively; values in parentheses represent $t$ statistics. The same goes below.

Table 4. Granger causality test.

\begin{tabular}{cccc}
\hline Null Hypothesis: & Obs & F-Statistic & Prob. \\
\hline NCSKEW_40 does not Granger Cause NCSKEW_20 & 4388 & 0.40440 & 0.6676 \\
NCSKEW_20 does not Granger Cause NCSKEW_40 & & 4.97845 & 0.0073 \\
\hline
\end{tabular}

The above analysis supports the view that high liquidity can reduce the risk of a stock market crash. In addition, it can also be obtained that the larger the rolling parameter $n$, the less sensitive the crash risk index, and the worse the model performance.

\subsection{Regression Analysis of Weekly Sample Models}

According to Equation (2), regression analysis of the weekly crash risk indicator $N C S K E W_{t}$ with different rolling parameter values is performed, and the results are as in Table 5.

Analyze Table 5. Except for the model represented by $n=40$, the t-tests for the independent variables $\operatorname{Liq}_{t}$ of the other models all passed significantly. In addition, the regression coefficient of the independent variable $\mathrm{Liq}_{t}$ is negative when $n=20$, which is consistent with the model results in Table 4 . However, the regression coefficients of the independent variables $L i q_{t}$ are all positive when the models represented by $n=60, n=80$, and $n=100$. This is a paradoxical result: a negative value means that high liquidity can reduce the risk of a stock market crash, while a positive value means that high liquidity increases the risk of a stock market crash. So, has it been reduced or worsened? This article considers it to be lower. The reason has been mentioned above: the crash risk is most relevant to recent information. The larger the rolling parameter $n$, the less sensitive the crash risk indicator, and the worse the model performance. Figure 1 further verifies this point. The upper part of Figure 1 represents the weekly closing price data of the Shanghai Stock Exchange Index from January 1, 2009 to December 31, 2018, that is, weekly sample data. The five curves in the lower half represent the weekly $N C S K E W_{t}$ of different parameter values, that is, the risk 
Table 5. NCSKEW regression results of weekly sample data.

\begin{tabular}{cccccc}
\hline \multirow{2}{*}{ variable } & NCSKEW $_{t}$ & NCSKEW $_{t}$ & NCSKEW $_{t}$ & NCSKEW $_{t}$ & NCSKEW $_{t}$ \\
\cline { 2 - 6 } & $(n=20)$ & $(n=40)$ & $(n=60)$ & $(n=80)$ & $(n=100)$ \\
\hline \multirow{2}{*}{ Liq $_{t}$} & $-2.5214^{* *}$ & -0.8843 & $2.3083^{* *}$ & $2.7971^{* *}$ & $4.9708^{* * *}$ \\
& $(-2.4256)$ & $(-0.7419)$ & $(1.9982)$ & $(2.2860)$ & $(4.3827)$ \\
\multirow{2}{*}{ Ret $_{t}$} & $-3.2611^{* *}$ & -1.3332 & $-2.4742^{*}$ & $-2.9277^{* *}$ & $-2.8958^{* *}$ \\
& $(-2.2208)$ & $(-1.1004)$ & $(-1.6954)$ & $(-2.0386)$ & $(-2.2207)$ \\
& $17.8500^{* * *}$ & $40.2971^{* * *}$ & $11.8729^{* * *}$ & $8.1849^{*}$ & 4.2617 \\
Sigma $_{t}$ & $(4.8491)$ & $(14.6555)$ & $(2.8457)$ & $(1.8086)$ & $(0.9097)$ \\
\hline
\end{tabular}

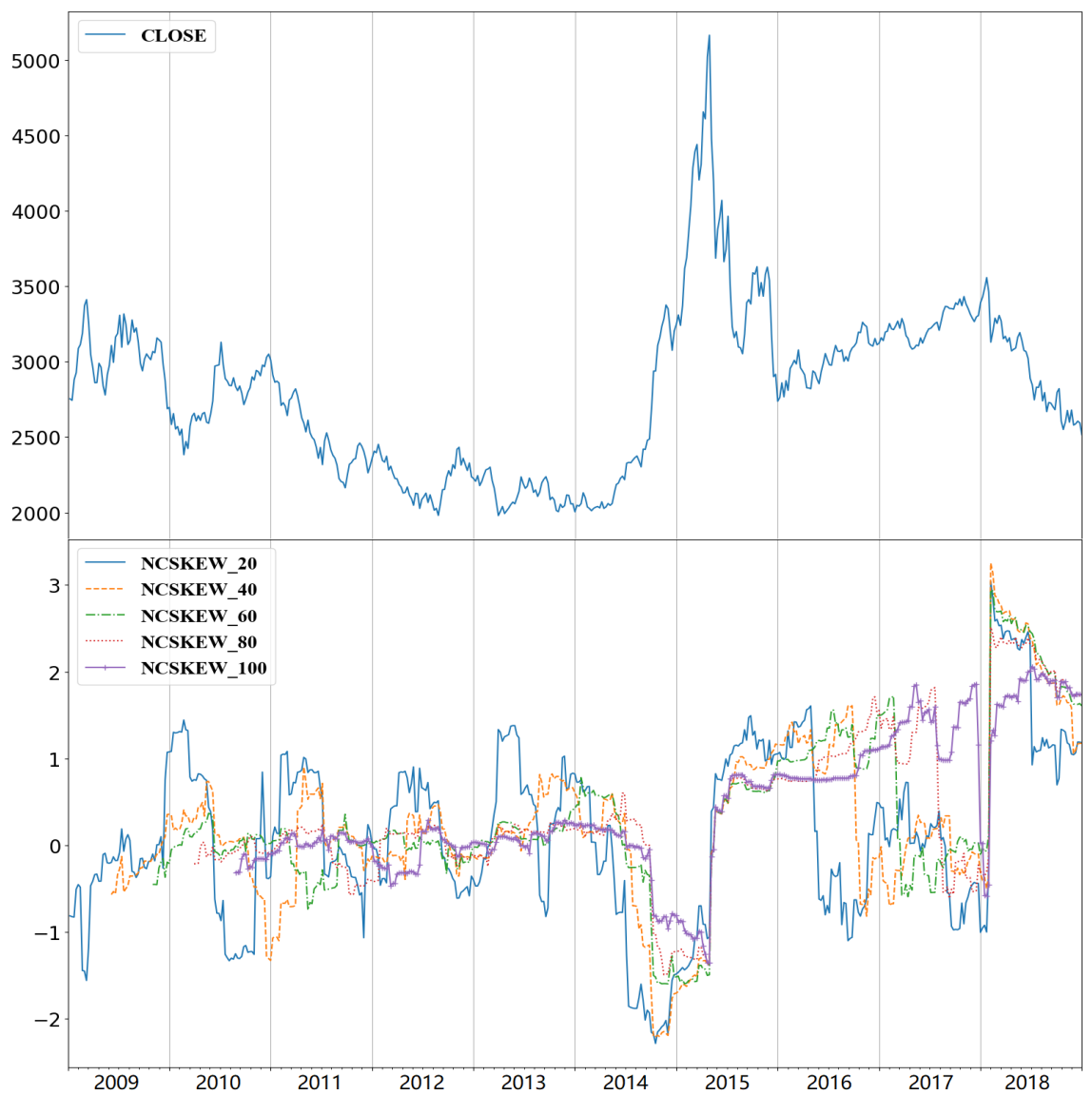

Figure 1. Weekly closing price and crash risk indicators of Shanghai Stock Index.

curve of the crash. The relationship between the two should be: When the stock market plunges downward, the curve of the risk of collapse should soar upward. It can be clearly seen from Figure 1 that this is indeed the case. The upper closing price curve and the lower crash risk value curve show a clear negative correlation. For example, at the intersection between 2009 and 2010, the index plummeted, and the curve below clearly formed a peak. This was the case in mid-2012 and early 2013.

In addition, it can be clearly seen from Figure 1 that the relationship between 
the five curves has the same trend and lags sequentially. This phenomenon was particularly evident in the period from early 2016 to the end of 2017. Moreover, it can also be seen that the inverse correspondence between the curve NCSKEW_20 and the weekly closing price curve above is closer and more positive than the other four curves. For almost every wave of the broader market, the curve NCSKEW_20 responds more quickly and intense than the other four curves. Its peaks and valleys basically include the local maximums and localities of the following five curves. This phenomenon was very obvious during the period from the end of 2009 to the end of 2013. In a more professional expression: the indicator NCSKEW_20 is more sensitive than the other four indicators, and can quickly and timely capture the signal of a stock market crash, while the other four have different degrees of passivation.

This also validates the point made above: the risk of a crash is most relevant to recent information. When the value of the rolling parameter $n$ is too large, after covering more information before the market fluctuations are flat, the response of the crash risk indicator will become sluggish. It appears smoother in the graphics. Of course, this is relative to the curve NCSKEW_20. In fact, the standard deviations of the five curves are $0.9977,0.9493,0.9039,0.8643$, and 0.7737 , which are indeed lower in order and gradually flatter. Based on this, this article abandoned the last four curves, that is, the last four models, and chose the first curve to support the view that high liquidity can reduce the risk of stock market crashes.

\subsection{Robustness Test}

In order to further strengthen the robustness of the research conclusions, another index proposed by Chen et al. (2001) was selected to replace NCSKEW as the index to measure the risk of stock market crash. The calculation method is as follows:

$$
\text { DUVOL }_{t}=\ln \left\{\left[\left(n_{u}-1\right) \sum_{\text {down }} R_{t}^{2}\right] /\left[\left(n_{d}-1\right) \sum_{u P} R_{T}^{2}\right]\right\}
$$

In the Formula (5), $R_{t}$ also comes from Formula (1). $n_{u}$ and $n_{d}$ are the number of days (weeks) in which the market rate of return is greater than (less than) the average rate of return within the rolling parameter $n$ days (weeks), $n=n_{u}+n_{d}$. $D_{U V O L}$ indicates the volatility of the market on the $t$ day (week). The larger value of DUVOL means the higher risk of a market crash.

Similarly, perform a stationary test on this indicator.

It can be seen in Table 6 that the daily DUVOL indicator did not pass the stability test, but weekly DUVOL passed it. Therefore, according to Formula (2), regression analysis of the weekly index is as in Table 7.

It can be seen from Table 7 that the t-test results of the regression coefficients of the independent variable $L i q_{t}$ under each model all pass significantly, and the regression coefficients are all negative values, with values ranging from -0.5070 to -0.1410 . Such empirical results are consistent with the results obtained above using NCSKEW as an indicator of crash risk, supporting the view that high liquidity can reduce the risk of stock market crashes. 
Table 6. Duvol stationary test.

\begin{tabular}{ccccccc}
\hline variable & Obs & t-Static & Prob & $1 \%$ level & $5 \%$ level & $10 \%$ level \\
\hline Daily Duvol & 2410 & -1.8889 & 0.3379 & -3.4329 & -2.8625 & -2.5673 \\
Weekly Duvol & 490 & -3.1600 & 0.0231 & -3.4436 & -2.8673 & -2.5699 \\
\hline
\end{tabular}

Table 7. DUVOL $L_{t}$ regression results of weekly sample data.

\begin{tabular}{|c|c|c|c|c|c|}
\hline \multirow{2}{*}{ variable } & $D U V O L_{t}$ & $D U V O L_{t}$ & $D U V O L_{t}$ & $D U V O L_{t}$ & $D U V O L_{t}$ \\
\hline & $(n=20)$ & $(n=40)$ & $(n=40)$ & $(n=80)$ & $(n=100)$ \\
\hline \multirow{2}{*}{$\operatorname{Liq}_{t}$} & $-0.1410^{* *}$ & $-0.4941^{* * *}$ & $-0.4851^{* * *}$ & $-0.5070^{* * *}$ & $-0.4870^{* * *}$ \\
\hline & $(-1.9540)$ & $(-5.5418)$ & $(-4.5617)$ & $(-3.5460)$ & $(-2.8878)$ \\
\hline \multirow{2}{*}{$\operatorname{Ret}_{t}$} & -0.0397 & $0.2307^{\star *}$ & $0.3434^{\star *}$ & $0.4147^{\star *}$ & $0.4682^{* *}$ \\
\hline & $(-0.3895)$ & $(2.0846)$ & $(2.5565)$ & $(2.4709)$ & $(2.4148)$ \\
\hline \multirow{2}{*}{$\operatorname{Sigma}_{t}$} & -0.3502 & $1.0275^{\star * *}$ & $0.8177^{* *}$ & 0.5467 & -0.6262 \\
\hline & $(-1.3701)$ & $(3.4757)$ & $(2.1291)$ & $(1.0338)$ & $(-0.8989)$ \\
\hline
\end{tabular}

\section{Research Conclusion and Policy Recommendations}

To sum up, this paper through the empirical test of the daily and weekly data of the Shanghai Composite Index, regression analysis of the two crash risk indicators, found that high liquidity can reduce the crash risk of the stock market. In view of the importance of liquidity in market operation, this article proposes the following policy recommendations:

First, a complete liquidity monitoring and early warning mechanism has been established. Liquidity is one of the market's health indicators: too high liquidity means that the market is overheating and there is a risk of creating a bubble; too low liquidity means that the market is too cold and investor transactions are blocked. Whether it is too high or too low, it is not what the market is happy to see. As a supervisor, it is necessary to monitor the operation of the main liquidity indicators in the market, and to remind the market in a timely manner based on the performance of the liquidity indicators in accordance with market conditions. When necessary, moderate intervention in market liquidity can be achieved through administrative means.

Second, control the market's leverage. Leverage is a double-edged sword, which can magnify both profits and losses. The "lever bull" in 2015 is still fresh in memory. The influx of natural capital has created a wave of momentum like a rainbow. However, under the order of clearing HOMS off-site funding, the imaginary high-rise buildings collapsed. There must be awe in leverage. Leveraged funds entering the market often involve various financial institutions such as banks and securities. It is necessary to strengthen the coordination and supervision capabilities of various competent authorities, and if necessary, establish corresponding emergency mechanisms to improve the ability to deal with emergency risk events.

Third, strengthen supervision of Floating capital. Floating capital is commonly known as "hot money", which refers to speculators with huge amounts of 
funds and fast-in and fast-out operations. These characteristics determine that they can quickly bring liquidity to the market and quickly remove liquidity from the market. Extreme instability is an accelerator of rapid stock price changes. It is necessary for the supervisory authorities to supervise them properly in order to help maintain market stability.

\section{Acknowledgements}

Project supported by the National Natural Science Foundation of China (Project No. 71373135).

\section{Conflicts of Interest}

The authors declare no conflicts of interest regarding the publication of this paper.

\section{References}

Admati, A. R. \& Pfleiderer, P. (2009). The "Wall Street Walk" and Shareholder Activism: Exit as a Form of Voice. Review of Financial Studies, 22, 2645-2685. https://doi.org/10.1093/rfs/hhp037

Amihud, Y. (2002). Illiquidity and Stock Returns: Cross-Section and Time-Series Effects. Journal of Financial Markets, 5, 31-56. https://doi.org/10.1016/S1386-4181(01)00024-6

Bhide, A. (1993). The Hidden Costs of Stock Market Liquidity. Journal of Financial Economics, 34, 31-35. https://doi.org/10.1016/0304-405X(93)90039-E

Brunnermeier, M. K., \& Pedersen, L. H. (2008). Market Liquidity and Funding Liquidity. Review of Financial Studies, 22, 2201-2238. https://doi.org/10.1093/rfs/hhn098

Chang, X., Chen, Y. Y., \& Zolotoy, L. (2016). Stock Liquidity and Stock Price Crash Risk. Journal of Financial and Quantitative Analysis, 52, 1605-1637. https://doi.org/10.1017/S0022109017000473

Chen J., Hong, H., \& Stein, J. C. (2001). Forecasting Crashes: Trading Volume, Past Returns, and Conditional Skewness in Stock Prices. Journal of Financial Economics, 61, 345-381. https://doi.org/10.1016/S0304-405X(01)00066-6

Christoffersen, P., Feunou, B., \& Jeon, Y. (2016). Time-Varying Crash Risk: The Role of Market Liquidity. Staff Working Papers. https://doi.org/10.2139/ssrn.2797308

Edmans, A. (2009). Blockholder Trading, Market Efficiency, and Managerial Myopia. The Journal of Finance, 64, 2481-2513. https://doi.org/10.1111/j.1540-6261.2009.01508.x

Fang, V. W., Tian, X., \& Tice, S. (2014). Does Stock Liquidity Enhance or Impede Firm Innovation? The Journal of Finance, 69, 2085-2125. https://doi.org/10.1111/jofi.12187

Holden, C. W., Jacobsen, S. E., \& Subrahmanyam, A. (2014). The Empirical Analysis of Liquidity. Foundation and Trends in Finance, 8, 263-365.

https://doi.org/10.1561/0500000044

Holmstrom, B., \& Tirole, J. (1993). Market Liquidity and Performance Monitoring. Journal of Political Economy, 101, 678-709. https://doi.org/10.1086/261893

Maug, E. (1998). Large Shareholders as Monitors: Is There a Trade-Off between Liquidity and Control? Journal of Finance, 53, 65-98. https://doi.org/10.1111/0022-1082.35053

Persaud, A. (2007). Liquidity Black Hole (pp. 91-150). Beijing: China Finance Press.

Porter, M. E. (1991). Capital Disadvantage: America's Failing Capital Investment System. Harvard Business Review, 70, 65-82. 